Institute for Neuromuscular Research, The Children's Hospital at Westmead, Locked Bag 4001, Westmead, NSW 2145, Autralia. E-mail: joshuab2@chw.edu,au).

COMMENT. CMT1A is a demyelinating neuropathy characterized by progressive muscle weakness and atrophy. The peroneal muscles are involved first, causing a striking stork-like gait, and weakness and atrophy of the upper extremities is initially limited to the intrinsic muscles of the hands. The authors comment that the hand involvement is frequently under-recognized in the early stages.

\title{
HEARING LOSS IN FACIOSCAPULOHUMERAL DYSTROPHY
}

The clinical presentation of facioscapulohumeral dystrophy (FSHD) with unusual large $4 \mathrm{q} 35$ deletions was studied with attention to hearing loss. Hearing function was examined by otoscopy, audiometry and auditory-evoked brainstem responses. Data obtained from 6 patients with EcoRI 4q35 fragment size, ranging from 10 to $13 \mathrm{~kb}$, were compared with those of 28 similar subjects reported in the literature. Sensorineural hearing loss occurred in 4 patients who had an infantile-onset dystrophic phenotype. Hearing loss was associated with mental retardation in 3 and epilepsy in 2. Hearing was mildly impaired in the remaining 2 of 6 patients. When the data from 28 similar cases reported in the literature were combined with that from the 6 patients examined, $68 \%$ had auditory impairment. Hearing loss is a characteristic feature of FSHD patients with a large $4 \mathrm{q} 35$ deletion. When considering only cases with 10-11 kb fragment size, FSHD is associated with early-onset dystrophic phenotype, mental retardation in $92 \%$ and epilepsy in $58 \%$. (Trevisan CP, Pastorello E, Tomelleri G et al. Facioscapulohumeral muscular dystrophy: hearing loss and other atypical features of patients with large $4 \mathrm{q} 35$ deletions. Eur J Neurol Dec 2008;15:1353-1358 (Abstract)).

COMMENT. Facioscapulohumeral dystrophy with sensorineural hearing loss and Coats' syndrome was described by Taylor DA et al (Ann Neurol 1982;12:395). Coats' syndrome includes congenital retinal dysgenesis with telangiectasia and retinal detchment. A PubMed search of the literature found 8 reports of FSHD and sensorineural deafness, dating from 2008 to 1985 . One case with epilepsy was complicated by infantile spasms at 6 months of age, the dystrophy presenting at 3 years, and sensorineural deafness noted later (Akiyama C et al. No To Hattatsu 1991;23:395-399). All 6 patients reported with facial diplegia in the first year of life and subsequent development of FSHD had sensorineural deafness (Korf BR et al. Ann Neurol 1985;17:513-516).

\section{NEONATAL DISORDERS}

\section{HIPPOCAMPAL VOLUMES IN PRETERM INFANTS}

The relation between neonatal regional brain volumes and working memory deficits at age 2 years was investigated in 156 very preterm children born at the Royal Women's Hospital, Melbourne, Auatralia, prior to 30 weeks gestation or weighing $<1250 \mathrm{~g}$. Very preterm children who perseverated on the working memory task had significantly smaller 